Systematic re-evaluation of genes from candidate gene association studies in migraine using a large genome-wide association data set

de Vries, Boukje

2016-06

de Vries, B , Anttila , V , Freilinger, T, Wessman, M , Kaunisto, M A, Kallela, K M , Artto , V , Vijfhuizen , L S , Goebel , H , Dichgans, M , Kubisch , C , Ferrari , M D , Palotie , A , Terwindt, G M , van den Maagdenberg , A M J M \& Int Headache Genetics Consortium 2016 , ' Systematic re-evaluation of genes from candidate gene association studies in migraine using a large genome-wide association data set ' , Cephalalgia , vol. 36 , no. 7 , pp. 604-614 . https://doi.org/10.1177/0333102414566820

http://hdl.handle.net/10138/224082

https://doi.org/10.1177/0333102414566820

publishedVersion

Downloaded from Helda, University of Helsinki institutional repository.

This is an electronic reprint of the original article.

This reprint may differ from the original in pagination and typographic detail.

Please cite the original version. 


\title{
Systematic re-evaluation of genes from candidate gene association studies in migraine using a large genome-wide association data set
}

Cephalalgia

2016, Vol. 36(7) 604-6I4

(C) International Headache Society 2015 Reprints and permissions: sagepub.co.uk/journalsPermissions.nav DOI: $10.1|77 / 03331024| 4566820$ cep.sagepub.com

(S)AGE

\author{
Boukje de Vries', Verneri Anttila $2,3,4,5$, Tobias Freilinger ${ }^{6,7}$, \\ Maija Wessman $^{8,9}$, Mari A Kaunisto ${ }^{8,9}$, Mikko Kallela ${ }^{10}$, \\ Ville Artto $^{10}$, Lisanne S Vijfhuizen', Hartmut Göbel' ', \\ Martin Dichgans ${ }^{6,12}$, Christian Kubisch ${ }^{13}$, Michel D Ferrari ${ }^{14}$, \\ Aarno Palotie $2,3,5,8,15,16$, Gisela M Terwindt ${ }^{14}$, \\ Arn MJM van den Maagdenberg ${ }^{1,14}$ and on behalf of the \\ International Headache Genetics Consortium
}

\begin{abstract}
Background: Before the genome-wide association (GWA) era, many hypothesis-driven candidate gene association studies were performed that tested whether DNA variants in genes that had been selected based on prior knowledge about migraine pathophysiology were associated with migraine. Most studies involved small sample sets without robust replication, thereby making the risk of false-positive findings high. Genome-wide marker data of thousands of migraine patients and controls from the International Headache Genetics Consortium provide a unique opportunity to re-evaluate key findings from candidate gene association studies (and other non-GWA genetic studies) in a much larger data set.

Methods: We selected 2 I genes from published candidate gene association studies and six additional genes from other non-GWA genetic studies in migraine. Single nucleotide polymorphisms (SNPs) in these genes, as well as in the regions $500 \mathrm{~kb}$ up- and downstream, were inspected in IHGC GWAS data from 5175 clinic-based migraine patients with and without aura and 13,972 controls.

Results: None of the SNPs in or near the 27 genes, including the SNPs that were previously found to be associated with migraine, reached the Bonferroni-corrected significance threshold; neither when analyzing all migraine patients together, nor when analyzing the migraine with and without aura patients or males and females separately.

Conclusion: The available migraine GWAS data provide no clear evidence for involvement of the previously reported most promising candidate genes in migraine.
\end{abstract}

\section{Keywords}

Migraine, candidate genes, SNP, GWAS data

Date received: I5 December 2013; revised: 22 September 20I4; accepted: 6 December 2014

\footnotetext{
'Department of Human Genetics, Leiden University Medical Center, the Netherlands

${ }^{2}$ Analytical and Translational Genetics Unit, Department of Medicine, Massachusetts General Hospital, USA

${ }^{3}$ Program in Medical and Population Genetics, Broad Institute of MIT and Harvard, USA

${ }^{4}$ Harvard Medical School, USA

${ }^{5}$ Stanley Center for Psychiatric Research, Broad Institute for Harvard and MIT, USA

${ }^{6}$ Institute for Stroke and Dementia Research, Klinikum der Universität München, Ludwig-Maximilians-Universität, Germany

${ }^{7}$ Department of Neurology and Epileptology and Hertie-Institute for Clinical Brain Research, University of Tübingen, Germany

${ }^{8}$ Institute for Molecular Medicine Finland (FIMM), University of Helsinki, Finland
}

\footnotetext{
${ }^{9}$ Institute of Genetics, Folkhälsan Research Center, Finland

${ }^{10}$ Department of Neurology, Helsinki University Central Hospital, Finland

"'Kiel Pain and Headache Center, Germany

${ }^{12}$ Munich Cluster for Systems Neurology (SyNergy), Germany

${ }^{13}$ Institute of Human Genetics, University of Ulm, Germany

${ }^{14}$ Department of Neurology, Leiden University Medical Center, the Netherlands

${ }^{15}$ Psychiatric and Neurodevelopmental Genetics Unit, Department of Medicine, Massachusetts General Hospital, USA

${ }^{16}$ Department of Neurology, Massachusetts General Hospital, USA

B.d.V. and V.A. contributed equally to this manuscript.

Corresponding author:

Gisela M. Terwindt, Department of Neurology, Leiden University Medical Center, Albinusdreef 2, PO Box 9600, 2300 RC Leiden, The Netherlands. Email: G.M.Terwindt@lumc.nl
} 


\section{Introduction}

Disease susceptibility for common disorders, including migraine, is thought to be conferred by a combination of environmental factors and genetic factors that are either common (i.e. with a minor allele frequency (MAF) larger than $5 \%$ in the population) or rare. In the past decades, many genetic association studies have been performed by testing DNA variants in dozens of candidate genes in order to identify genetic factors for migraine $(1,2)$. Genes were selected based on the hypothesis that the respective pathway was implicated in migraine pathophysiology; e.g. genes that play a role in serotonin and dopamine pathways (3). The majority of the studies investigated only a single or a limited number of DNA variants per gene and therefore had a low a priori likelihood of targeting the correct variant that confers disease susceptibility. Moreover, rather low numbers of cases and controls (rarely more than 300 per group) were studied, resulting in limited statistical power to evaluate their association. For the majority of the associations no replication of the findings in independent cohorts was provided (for review, see de Vries et al. (1)). Consequently, many of the associations may in fact represent false-positive findings. Similar experiences have been observed in other common diseases (4-6).

Over the last few years, genome-wide association studies (GWAS) have become the state-of-the-art approach to identify genetic factors involved in common disorders. Unlike candidate gene association studies that are hypothesis driven, GWAS are hypothesis free and hypothesis generating in nature. Typically they involve large cohorts of at least several thousand patients and controls and test the association with disease of hundreds of thousands of single nucleotide polymorphisms (SNPs) distributed over the genome (7). Importantly, initial association findings are always scrutinized by follow-up testing in multiple independent replication cohorts. Therefore, the GWAS approach is less susceptible to false-positive results and more powerful than candidate gene association studies. Two GWA studies that investigated large numbers of migraine cases from clinic-based cohorts and controls have been published $(8,9)$. One study investigated migraine with aura (MA) (with 2731 cases and 10,747 controls) and revealed a single genome-wide significant migraine susceptibility locus on chromosome 8q22.1 that pinpointed the $M T D H$ gene as the possible disease-causing gene in this region (8). The other study investigated migraine without aura (MO) (with 2326 cases and 4580 controls) and yielded four additional migraine susceptibility loci on 1q22, 3p24, 6p24 and $9 \mathrm{q} 33$ presenting evidence for involvement of the MEF2D, TGFBR2, PHACTR1 and ASTN2 genes, respectively (9). The latter study also confirmed genetic associations of SNPs in the TRPM8 and LRPI genes ( $2 q 37$ and $12 q 13$, respectively) that had previously been identified as migraine susceptibility loci in a population-based GWA study (with 5122 cases and 18,108 controls) (10). A recent large meta-analysis (with 23,285 cases and 95,425 controls) that studied patients from clinic-based as well as population-based cohorts confirmed these loci and provided evidence for five additional migraine susceptibility loci (11). Notably, none of these genome-wide significant gene loci overlapped with genes that had been selected for candidate gene association studies in migraine.

The availability of GWAS data provides a unique opportunity to re-evaluate key findings from previous genetic studies in a much larger data set. We investigated 27 genes. Twenty-one genes were previously reported to be associated with migraine in candidate genes-based association studies. Three genes had been identified by positional cloning studies in families with familial hemiplegic migraine (FHM), a monogenic subtype of MA (12-14). Three genes came from direct sequencing of candidate genes in families and patients with monogenic migraine or common migraine (15-17). As the majority of the original studies investigated migraine patients who had been collected via specialized headache centers (i.e. patients who are clinic-based), we restricted our investigations to GWAS data of clinic-based migraine patients only $(8,9,11)$.

\section{Materials and methods}

\section{Selection of candidate genes for re-evaluation in the International Headache Genetics Consortium (IHGC) GWA data set}

Genes were selected for re-evaluation in the IHGC GWAS data set based on the results of a literature search of candidate gene association studies in migraine. We included studies that had investigated at least 300 migraine patients and 300 controls of Caucasian origin. From these studies, we selected only those genes for which at least nominally significant, uncorrected $p$ values $(p<0.05)$ were reported for one or more SNPs (see list of genes in Table 1). In addition, we selected genes from nonGWA genetic studies of migraine, namely the three FHM genes (CACNA1A (12), ATPIA2 (13) and SCN1A (14)) and three genes in which possibly causal mutations had been identified by a candidate gene sequencing approach, i.e. SLC1A3 (which encodes the EAAT1 glutamate transporter) (15), SLC4A4 (twhich encodes the NbCel protein) (16), and KCNK18 (which encodes the TRESK protein) (17) (Table 2). 
Table I. Summary of candidate gene association studies performed for migraine that reported at least nominal evidence for association $(p<0.05$ for a single SNP) and that contained at least 300 cases and controls.

\begin{tabular}{|c|c|c|c|c|}
\hline Gene & $\begin{array}{l}\text { Cases }(n)^{\mathrm{a}} \\
\text { Migraine (MA/MO) }\end{array}$ & $\begin{array}{l}\text { Controls } \\
(n)\end{array}$ & $\begin{array}{l}\text { Associated allele with } \\
\text { phenotype }(p \text { value })^{\mathrm{b}}\end{array}$ & Reference \\
\hline MTHFR & $\begin{array}{l}652(465 / 187) \\
413(187 / 226) \\
2961(2170 / 791) \\
477(124 / 353)\end{array}$ & $\begin{array}{l}320 \\
1212 \\
3844 \\
1402\end{array}$ & $\begin{array}{l}\text { 677T: NS }(p=0.017 /-) \\
\text { 677T: }-(p<0.006 / \mathrm{NS}) \\
\text { 677T: NS }(p=0.0005 / \mathrm{NS}) \\
\text { 677T: NS }(p=0.02 /-)\end{array}$ & $\begin{array}{l}\text { Lea et al. } 2004 \text { (18) } \\
\text { Scher et al. } 2006(19) \\
\text { Rubino et al. } 2009(20) \\
\text { Samaan et al. } 201 \text { I (2I) }\end{array}$ \\
\hline DBH & $\begin{array}{r}830(588 / 242) \\
650(650 /-)\end{array}$ & $\begin{array}{l}500 \\
650\end{array}$ & $\begin{array}{l}-102 \mathrm{IT}: p=0.004(p=0.01 \mathrm{I} / \mathrm{NS}) \\
\mathrm{rs} 2097629:-(p=0.01 /-)\end{array}$ & $\begin{array}{l}\text { Fernandez et al. } 2009(22) \\
\text { Todt et al. } 2009(23)\end{array}$ \\
\hline DRD I & $543(318 / 225)$ & 561 & rs251937: $p=0.0261(-/-)$ & Corominas et al. 2009 (24) \\
\hline DRD2 & $\begin{array}{l}650(650 /-) \\
543(318 / 225)\end{array}$ & $\begin{array}{l}650 \\
561\end{array}$ & $\begin{array}{l}\text { rs7। 3 I056: }-(p=0.006 /-) \\
\text { rs2283265: } p=0.0030(p=0.037 / p=0.008 I)\end{array}$ & $\begin{array}{l}\text { Todt et al. } 2009(23) \\
\text { Corominas et al. } 2009(24)\end{array}$ \\
\hline DRD3 & $543(318 / 225)$ & 561 & rs3732790: $p=0.0033(-/-)$ & Corominas et al. 2009 (24) \\
\hline SLC6A3 & $543(318 / 225)$ & 561 & rs40184: $-(p=0.03 /-)$ & Todt et al. 2009 (23) \\
\hline $\mathrm{TH}$ & $543(318 / 225)$ & 561 & rs2070762: $p=0.0035(\mathrm{NS} / \mathrm{P}=0.036)$ & Corominas et al. 2009 (24) \\
\hline EDNRA & $850(850 /-)$ & 890 & $\begin{array}{l}\text { rs2048894: }-(p=0.015 /-) \\
\text { rs5334: }-(p=0.046 /-)\end{array}$ & Tikka-Kleemola et al. 2009 (25) \\
\hline$E D N R B$ & $850(850 /-)$ & 890 & rs2329047: $-(0.035 /-)$ & Tikka-Kleemola et al. 2009 (25) \\
\hline STXIA & $569(407 / / 29)$ & 720 & rs941298: $p=0.004(\mathrm{NS} / p=0.008)$ & Tropeano et al. $2012(26)$ \\
\hline TRPVI & $1040(490 / 650)$ & 1037 & rs22274I: $p=0.03(\mathrm{NS} / \mathrm{NS})$ & Carreno et al. 2012 (27) \\
\hline TRPV3 & $1040(490 / 650)$ & 1037 & rs7217270: NS $(p=0.02 / N S)$ & Carreno et al. 2012 (27) \\
\hline FSHR & $356(198 / 158)$ & 374 & Rs6166: NS $(p=0.03 / \mathrm{NS})$ & Oterino et al. $2008(28)$ \\
\hline ESRI & $\begin{array}{l}484(360 / / 24) \\
898(898 /-)\end{array}$ & $\begin{array}{l}484 \\
900\end{array}$ & $\begin{array}{l}\text { 594A: } p=0.003(p=0.01 / p=0.02) \\
\text { rs65571 } 70, r s 2347867, r s 6557171, \\
\text { rs } 4870062 \text { and } r s 1801132 \\
(p \text { values } 0.007-0.034)\end{array}$ & $\begin{array}{l}\text { Colson et al. } 2004(29) \\
\text { Kaunisto et al. } 2006(30)\end{array}$ \\
\hline & $356(198 / 158)$ & 374 & rs|80I|32: $p=0.03(p=0.045 / \mathrm{NS})$ & Oterino et al. $2008(28)$ \\
\hline ESR2 & $356(198 / 158)$ & 374 & 2039G: NS $(p=0.0 \mathrm{I} / \mathrm{NS})$ & Oterino et al. $2008(28)$ \\
\hline$P G R$ & $509(37 / / 138)$ & 454 & PROGINS ins: $p=0.02(\mathrm{NS} / p=0.008)$ & Colson et al. 2005 (3I) \\
\hline TNFA & $299(38 / 261)$ & 306 & 308G: $p<0.00 \mathrm{I}(\mathrm{NS} / p<0.00 \mathrm{I})$ & Rainero et al. 2004 (32) \\
\hline SLC6A4 & $546(257 / 289)$ & 770 & STin2: $p=0.002(\mathrm{NS} / \mathrm{NS})$ & Schürks et al. 2010 (33) \\
\hline TPH2 & $503(2 \mid 4 / 289)$ & 515 & $\begin{array}{l}\text { Haplotype block with five SNPs: } \\
p=0.04(p=0.4 / p=0.006)\end{array}$ & Jung et al. 2010 (34) \\
\hline LTA & $439(65 / 327)$ & 382 & $-294 C: p=0.0002(p=0.0006 / p=0.0008)$ & Lee et al. 2007 (35) \\
\hline INSR & $827(377 / 450)$ & 765 & $\begin{array}{l}\text { c. } 2946-7 \mid 3 A: N S(p=0.002 / N S) \\
c .2842+\mid 45 \text { IA: NS }(p=0.007 / N S) \\
c .3255 T: N S(p=0.008 / N S)\end{array}$ & McCarthy et al. 200I (36) \\
\hline & $1278(\mid 278 /-)$ & 1337 & c. $2842+\mid 45 \mathrm{IT}:-(p=0.005 /-)$ & Netzer et al. 2008 (37) \\
\hline
\end{tabular}

MA: migraine with aura; MO: migraine without migraine; NS: not significant; -: not tested/not available; SNP: single nucleotide polymorphism; Ins: insertion; Del: deletion; VNTR: variable number of tandem repeats. ${ }^{a}$ Number of cases and ${ }^{b} p$ values are given for all migraine cases combined or, when specified between brackets, for migraine with aura cases only and/or migraine without aura cases only.

\section{GWAS data sets}

GWAS data of 2849 MA patients and 2326 MO patients from five clinic-based cohorts were collected via specialized headache centers in Finland, the Netherlands, and Germany $(8,9,11)$. Migraine diagnoses were based on a combination of questionnaires and/or individual interviews according to the International Classification of Headache Disorders, second edition (ICHD-II) guidelines (38) (Table 3).
Since the patients of nearly all candidate gene association studies came from clinic-based cohorts, we chose to investigate GWAS data only from clinic-based cohorts and not from population-based cohorts. An additional reason for including only clinic-based cohorts is that phenotypic information is less detailed and/or accurate in population-based cohorts, which would probably increase clinical and genetic heterogeneity. In all GWAS samples, standard quality control measures were applied; SNPs with call rates $<97 \%$, 
Table 2. Migraine candidate genes from family studies.

\begin{tabular}{|c|c|c|}
\hline Gene & Relation to migraine & Reference \\
\hline CACNAIA (FHMI) & $\begin{array}{l}\text { A linkage study identified CACNAIA as the first FHM gene. } \\
\text { CACNAIA encodes the } \alpha \text { I pore-forming subunit of Cav2.I cal- } \\
\text { cium channels. }\end{array}$ & Ophoff et al. 1996 (I2) \\
\hline ATPIA2 (FHM2) & $\begin{array}{l}\text { A linkage study identified ATPIA2 as the second FHM gene. ATPIA2 } \\
\text { encodes the } \alpha 2 \text { subunit of sodium-potassium pumps. }\end{array}$ & De Fusco et al. 2003 (13) \\
\hline SCNIA (FHM3) & $\begin{array}{l}\text { A linkage study identified SCNIA as the third FHM gene. SCNIA } \\
\text { encodes the } \alpha \text { I subunit of neuronal } \mathrm{Na}_{\vee} I . I \text { sodium channels. }\end{array}$ & Dichgans et al. 2005 (I4) \\
\hline SLCIA3/EAATI & $\begin{array}{l}\text { A mutation in a single case with SHM that was identified through } \\
\text { sequencing of the coding exons of SLCIA3 and presented first } \\
\text { evidence for SLCIA3 as an SHM gene. SLCIA3 encodes the } \\
\text { EAATI glutamate transporter. }\end{array}$ & Freilinger et al. 2010 (15) \\
\hline SLC4A4/NBCeI & $\begin{array}{l}\text { Homozygous mutations in SLC4A4 were reported in two sisters } \\
\text { with reported hemiplegic migraine, in addition to proximal renal } \\
\text { tubular acidosis and ocular abnormalities, and presented first } \\
\text { evidence for SLC4A4 as a migraine gene. SLC4A4 encodes the } \\
\mathrm{Na}^{+}-\mathrm{NCO}_{3}^{-} \text {cotransporter NBCel. }\end{array}$ & Suzuki et al. $2010(16)$ \\
\hline KCNKI8/TRESK & $\begin{array}{l}\text { A mutation in } K C N K I 8 \text { in a single family with familiar migraine was } \\
\text { identified in a candidate gene sequencing approach and pre- } \\
\text { sented first evidence for } K C N K I 8 \text { as a migraine gene. } K C N K I 8 \\
\text { encodes for the ion channel TRESK. }\end{array}$ & Lafrenière et al. 2010 (I7) \\
\hline
\end{tabular}

FHM: familial hemiplegic migraine; SHM: sporadic hemiplegic migraine; MA: migraine with aura.

MAF $<1 \%$ and/or excessive deviation from HardyWeinberg equilibrium (with $p<10^{-6}$ ) in either cases or controls were excluded. Individuals with a genotyping rate $<97 \%$ were excluded from the analyses (for more details, see Anttila et al. (11)).

Genome-wide marker data from 13,972 individuals from several pre-existing non-overlapping control cohorts that were population-matched to the cases were used as controls. The majority of the control cohorts were unselected for migraine status, implicating that they are expected to contain cases at the same frequency as the general population (Table 3). In the meta-analysis, SNPs missing from one of the studies, those with a MAF $<1 \%$, and/or those showing excess heterogeneity $\left(I^{2}>0.75\right)$ were excluded.

\section{Power calculation and significance threshold}

Data for the selected genes were extracted from the existing GWAS data from an interval containing the candidate gene and the flanking region $500 \mathrm{~kb}$ in each direction, to have a reasonable chance of covering possible regulatory effects for the targeted genes. The threshold for evaluating the significance of SNPs located in the tested gene regions was $2.19 \times 10^{-6}$, based on a Bonferroni correction for the number of unique SNPs that were tested $(0.05 / 22,774)$. Our GWAS sample (5175 cases and 13,972 controls) has 99\% power to detect association with an SNP under the assumption of an allele frequency (AF) of at least
0.05 and a relative risk of 1.5 or higher (allelic test, Genetic Power Calculator (http://pngu.mgh.harvard.edu/ purcell/gpc) (19)). These thresholds are in line with published candidate gene association studies. On a more stringent level, we have $84 \%$ power to detect a variant with a relative risk of 1.4. See Supplemental Table 1 for power calculations at a range of different allele frequencies (0.05-0.4) and relative risks (1.15$1.5)$.

\section{Effect size estimation}

We used the Genetic Power Calculator to estimate the genotype frequencies for a marker with similar MAF and odds ratio (OR) as the MTHFR C677T risk allele, while assuming a disease prevalence of $12 \%$, and using the sample size of the current study (5175 cases and 13,972 controls). A chi-square test for the resulting genotype frequencies was converted to a $p$ value using a two-degree of freedom (df) chi-square test.

\section{Results}

We used GWAS data of clinic-based migraine patients $(8,9,11)$ to re-evaluate 21 genes from migraine candidate gene association studies that had analyzed at least 300 migraine cases and controls and yielded associations of at least nominal $p$ values (Table 1). Six additional genes were included that came from other non-GWA studies, i.e. either candidate gene sequencing 


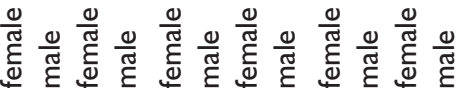
సे œ

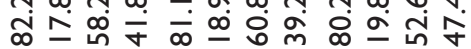

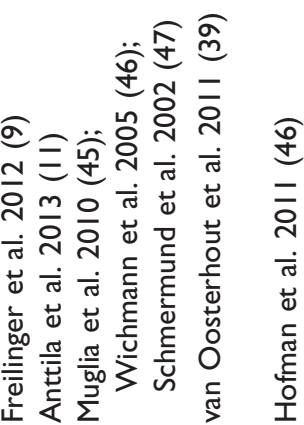

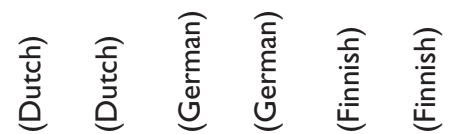

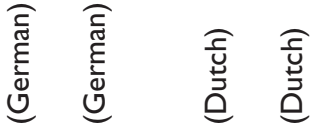

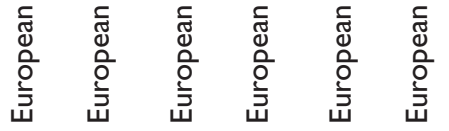

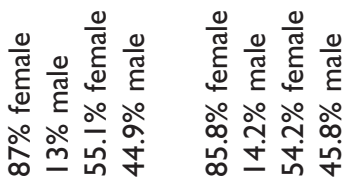

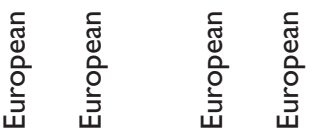

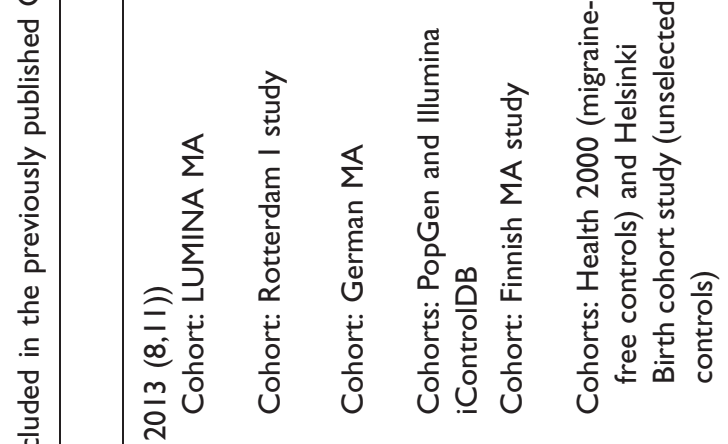

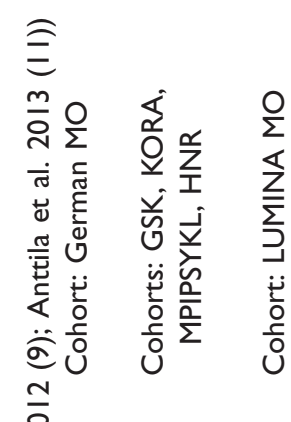

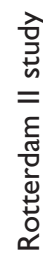

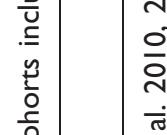

ind 0

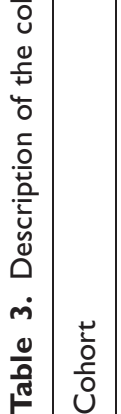

ग

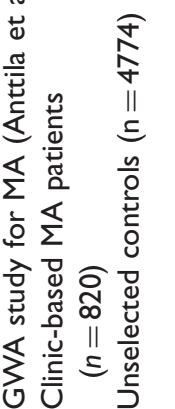

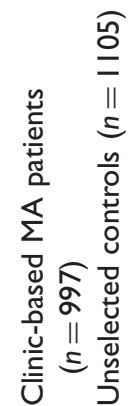

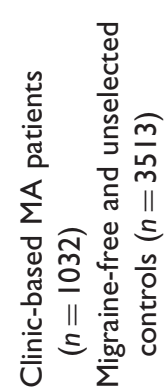

तै

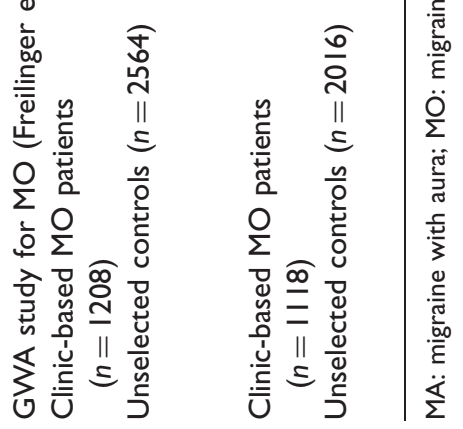


studies (KCNK18, SLC1A3, SLC4A4) in common migraine and/or hemiplegic migraine or linkage studies in FHM (CACNA1A, ATP1A2, SCN1A) (Table 2). Within the 27 gene regions we investigated 22,774 SNPs for association with migraine, applying a significance threshold for individual SNPs of $2.19 \times 10^{-6}$.

None of the SNPs, including the specific SNPs reported in the original publications (Supplemental Table 2), surpassed the significance threshold (Table 4, Supplemental Information). When analyzing MA and MO together, the best $p$ value was seen for SNP rs805287 $\left(p=1.08 \times 10^{-4}\right)$ that is located within the surrounding region of the TNFA and LTA genes. However, this SNP is located in a gene-dense region over $130 \mathrm{~kb}$ downstream of both genes (Figure 1(a)) and lies within the major histocompatibility complex locus, where overall levels of noise are higher because of the complex linkage disequilibrium structure (49). When analyzing MA and MO separately, for MA, again the best $p$ value was observed with an SNP ( $r$ 630379; $p=9.68 \times 10^{-6}$ ) at the border of the region surrounding the TNFA and LTA genes (Supplemental Information). For MO, the best $p$ value was seen for an SNP $\left(\operatorname{rs} 13024246, p=2.76 \times 10^{-5}\right)$ located in the FSHR gene region (Figure 1(b)) but this SNP was located far away from the originally selected gene. Only one gene region, namely that of the $D R D 3$ gene, showed a potentially interesting peak (with best associated SNP rs1486008, $p=2.88 \times 10^{-4}$; OR $\left.=1.19\right)$ within the previously implicated migraine gene (Figure 1(c)).

Although the chance of observing associations that are gender-specific is limited, as the vast majority of the migraine patients are women, we performed a genderspecific analysis for the total migraine group. Analyzing males and females separately did not reveal SNPs with gender-specific signals surpassing the significance threshold (Supplemental Table 3).

\section{Discussion}

For this study, we used the data of clinic-based GWA cohorts from the IHGC $(8,9,11)$ to re-evaluate key findings from previously published candidate gene association studies (and other genetic non-GWAS studies) in migraine. Our study included GWAS data from 5175 migraine patients and 13,972 controls and shows no significant association with migraine for any of the 27 genes (Table 4), despite the fact that our study had sufficient power $(>95 \%)$ to significantly detect genetic association signals for variants with an MAF $>0.05$ and a relative risk $>1.4$, as commonly presumed in the much smaller migraine candidate gene association studies. Only a few single SNPs for some of the 27 selected gene regions showed moderate evidence of association. Notably, none of the $p$ values of the
SNPs reported in the original publications surpassed the significance threshold (Supplemental Table 2), nor translated to the originally reported effect sizes. For example, the T-allele of the C677T polymorphism in the MTHFR gene, which showed significant association with migraine in various candidate gene association studies, did not show up in our study. Assuming an effect size of 1.5, which is in line with previously reported effect sizes for this variant in migraine (1821,50 ), and an MAF of $31 \%$ in the European population (51), our study would have produced a $p$ value below $1.46 \times 10^{-63}$. However, the T-allele showed no association with migraine in our study $(p=0.56$ for migraine; $p=0.51$ for MA; $p=0.11$ for MO); the lowest observed $p$ value in the MTHFR gene region in our study was $7.18 \times 10^{-4}$ for SNP rs11121783. Also for the other SNPs of the originally reported associations, our study should have produced low $p$ values; well below the set threshold of $2.19 \times 10^{-6}$, if the reported effect sizes would have replicated. These poor replication results indicate the limited value of small-scale genetic association studies at the single-gene or single-marker level, and emphasize the importance of using large, well-powered studies that are properly designed. This finding is in line with a recent review that supports the statistical observation that low power due to small sample sizes not only decreases the chance to detect a true effect, but also increases the chance that a significant finding does not reflect a true effect (52).

Based on current knowledge of effect sizes of common variants for many common diseases, the vast majority of the candidate gene association studies in the literature lacked sufficient power to detect an effect that can be realistically expected for a common allele in a common disorder like migraine. Therefore, the most probable reason for the lack of replication is that the results of the candidate gene association studies most likely represent false-positive findings. Although we did not show significant evidence for any of the genes previously implicated in common migraine as genetic migraine risk factors, we cannot, however, exclude the possibility that some of the previous findings are truepositive findings reflecting effects specific to a particular patient pool (such as individual families, in whom alleles that are rare in the general population can predominate). Possible additional reasons that could explain why we did not detect associations are that: (1) rare variants that may play a role may not be captured, either in candidate gene association studies or GWAS platforms, because of specific LD patterns that are not sufficiently reflected in the surrounding common markers; or (2) variants located in these candidate gene regions may play a role that have effect sizes too low to be detected, even with the current sample size, and will surface only with sample sizes 


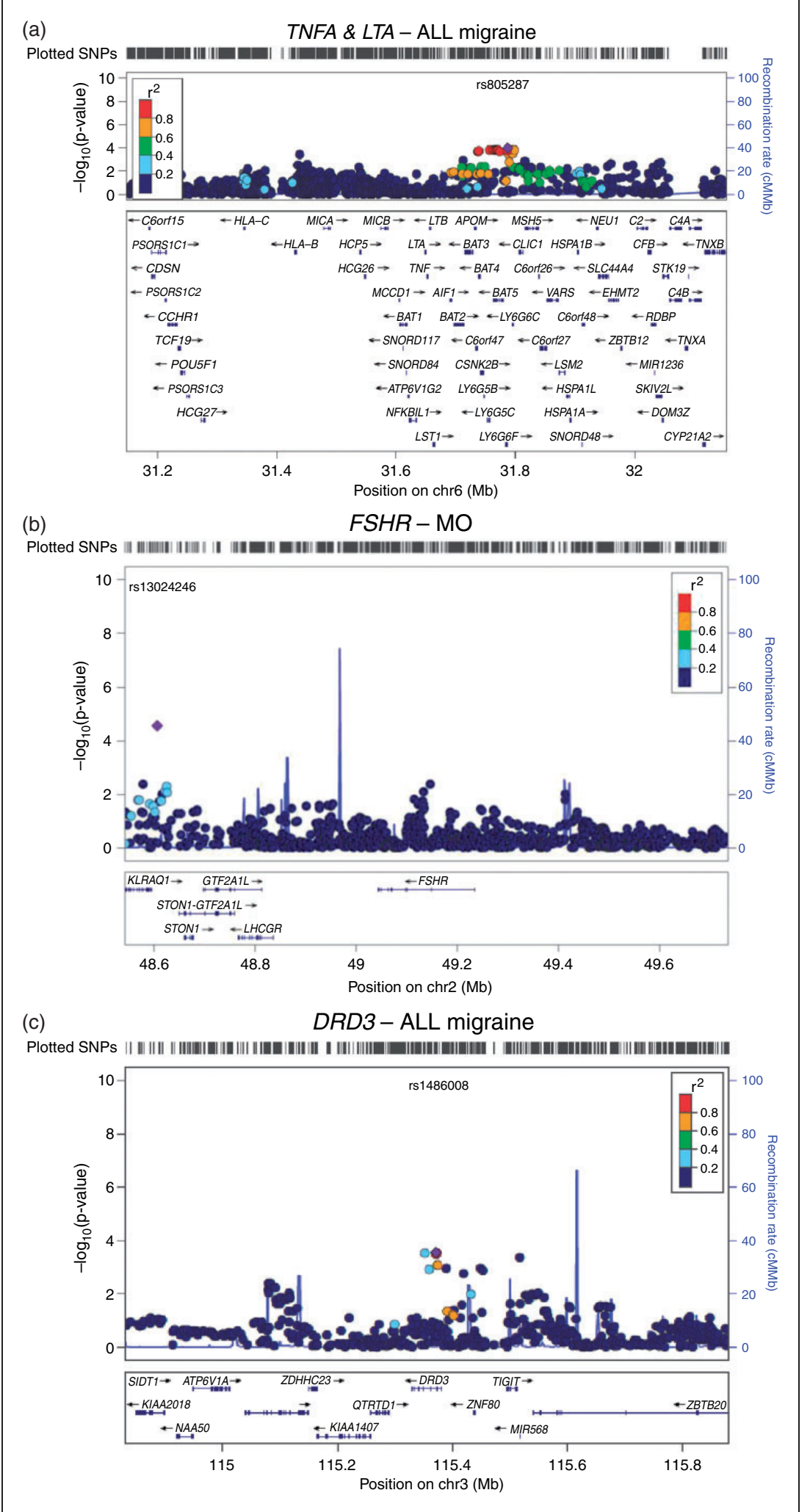

Figure I. Regional association plot (generated using LocusZoom) for SNPs within the (a) TNFA and LTA gene region and their association with migraine; (b) the FSHR gene region and their association with migraine without aura (MO); and (c) the DRD3 gene region and their association with migraine. The plots show the chromosomal position (based on NCBI build 36) for the SNP in the respective region against $-\log _{10} p$ values. The SNP with the highest association signal is represented as a purple diamond. Other SNPs are color coded according to the extent of LD with that specific SNP. SNP: single nucleotide polymorphism; NCBI: National Center for Biotechnology Information; LD: linkage disequilibrium. 


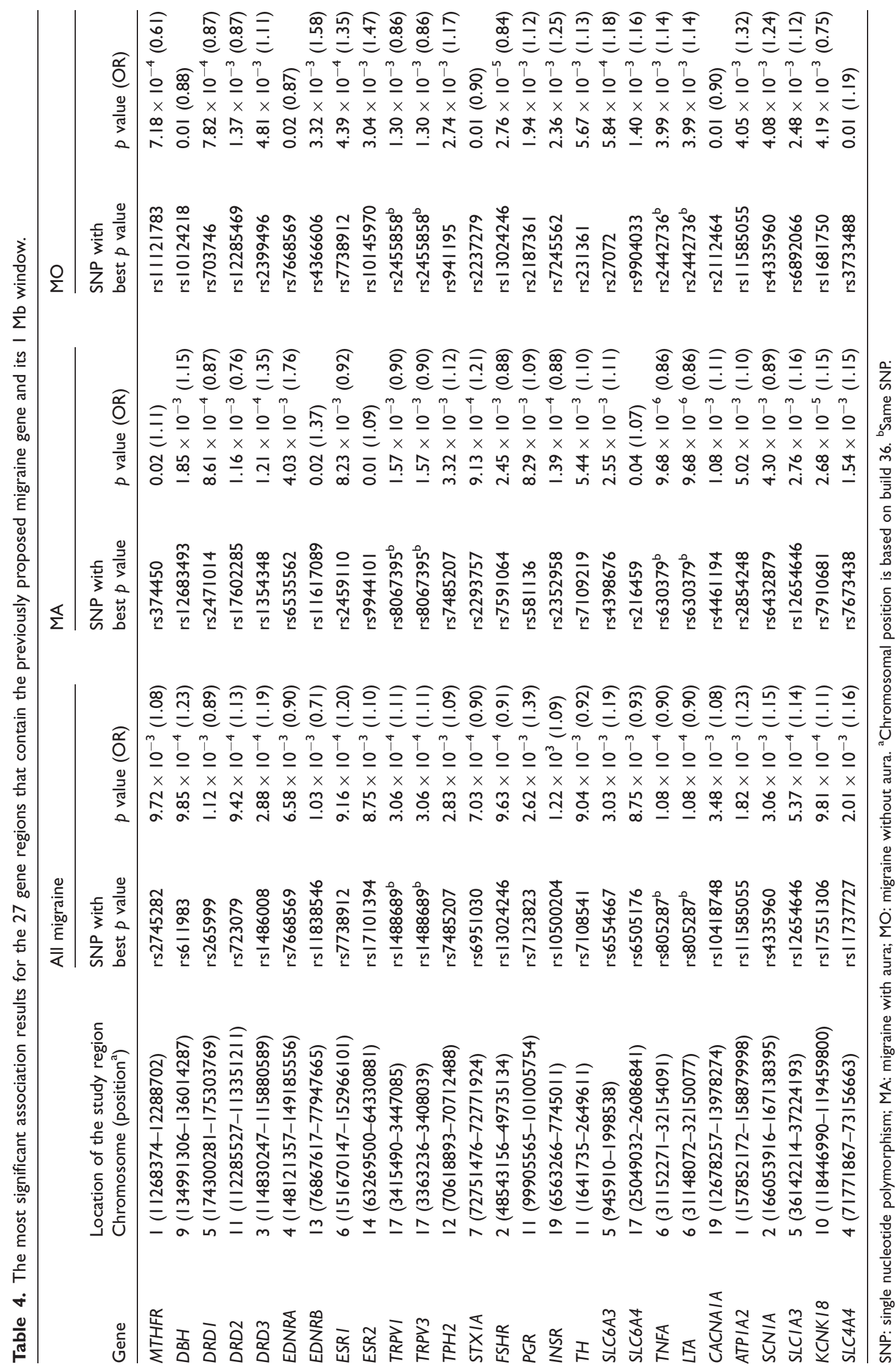


on the order of several hundreds of thousands cases and controls.

In conclusion, our analysis shows no evidence for the involvement of any of the selected 27 genes in migraine pathophysiology of common migraine. For future studies, other approaches should be considered to identify migraine susceptibility genes. This finding is in line with experiences of candidate gene association studies in other common diseases (53).

\section{Article highlights}

- Re-evaluation of previously reported migraine candidate gene hits shows no evidence for involvement in migraine pathology in a genome-wide association (GWA) data set.

- Small-scale genetic association studies lacking proper replication appear of limited value.

\section{Funding}

This work was supported by grants from the Netherlands Organization for the Health Research and Development (ZonMw) no. 90700217 and VIDI (ZonMw) no. 91711319 (to G.M.T.); the Netherlands Organisation for Scientific Research (NWO) VICI (918.56.602) and Spinoza (2009) grants (to M.D.F.); the EuroHead project (LSM-CT-2004504837); the EUROHEADPAIN project (grant number 602633); and the Center for Medical Systems Biology (CMSB) established in the Netherlands Genomics Initiative/ Netherlands Organisation for Scientific Research (NGI/ NWO), project nr. 050-060-409 (to R.R.F., M.D.F. and A.M.J.M.v.d.M.). The Wellcome Trust (grant number 098051 to AP); the Academy of Finland (grant number 251704 to AP, and 139795 to $\mathrm{MW}$ ); the Academy of Finland, Center of Excellence in Complex Disease Genetics, (grant numbers 213506 and 129680 to AP); ENGAGE Consortium, (grant agreement HEALTH-F4-2007- 201413); EU/SYNSYS- Synaptic Systems (grant number 242167 to AP); the Sigrid Juselius Foundation (to AP); the Folkhälsan Research Foundation (to MW); the Medicinska Understödsföreningen Liv \& Hälsa (to MW); the Helsinki University Central Hospital (to MK, VAr).

\section{Conflict of interest}

None declared.

\section{References}

1. de Vries B, Frants RR, Ferrari MD, et al. Molecular genetics of migraine. Hum Genet 2009; 126: 115-132.

2. Maher BH and Griffiths LR. Identification of molecular genetic factors that influence migraine. Mol Genet Genomics 2011; 285: 433-446.

3. Montagna P. Molecular genetics of migraine headaches: A review. Cephalalgia 2000; 20: 3-14.

4. Bevan S and Markus HS. Genetic profiles in ischaemic stroke. Curr Atheroscler Rep 2013; 15: 342.

5. McCarrol SA and Hyman SE. Progress in the genetics of polygenic brain disorders: Significant new challenges for neurobiology. Neuron 2013; 80: 578-587.

6. Petrovski S and Kwan P. Unraveling the genetics of common epilepsies: Approaches, platforms, and caveats. Epilepsy Behav 2013; 26: 229-233.
7. Manolio TA. Genomewide association studies and assessment of the risk of disease. $N$ Engl J Med 2010; 363: $166-176$

8. Anttila V, Stefansson H, Kallela M, et al. Genome-wide association study of migraine implicates a common susceptibility variant on 8q22.1. Nature Genet 2010; 42: 869-873.

9. Freilinger T, Anttila V, de Vries B, et al. Genome-wide association analysis identifies susceptibility loci for migraine without aura. Nat Genet 2012; 10: 777-782.

10. Chasman DI, Schürks M, Anttila V, et al. Genome-wide association study reveals three susceptibility loci for common migraine in the general population. Nat Genet 2011; 43: 695-698.

11. Anttila V, Winsvold BS, Gormley P, et al. Genome-wide meta-analysis identifies new susceptibility loci for migraine. Nat Genet 2013; 45: 912-917.

12. Ophoff RA, Terwindt GM, Vergouwe MN, et al. Familial hemiplegic migraine and episodic ataxia type- 2 are caused by mutations in the $\mathrm{Ca} 2+$ channel gene CACNL1A4. Cell 1996; 87: 543-552.

13. De Fusco M, Marconi R, Silvestri L, et al. Haploinsufficiency of $A T P 1 A 2$ encoding the $\mathrm{Na}+/ \mathrm{K}+$ pump alpha2 subunit associated with familial hemiplegic migraine type 2. Nat Genet 2003; 33: 192-196.

14. Dichgans M, Freilinger T, Eckstein G, et al. Mutation in the neuronal voltage-gated sodium channel SCN1A in familial hemiplegic migraine. Lancet 2005; 366: 371-377.

15. Freilinger T, Koch J, Dichgans M, et al. A novel mutation in SLC1A3 associated with pure hemiplegic migraine. J Headache Pain 2010; 11(Suppl 1): 90.

16. Suzuki M, Van Paesschen W, Stalmans I, et al. Defective membrane expression of the $\mathrm{Na}(+)$ $\mathrm{HCO}(3)(-)$ cotransporter $\mathrm{NBCe} 1$ is associated with familial migraine. Proc Natl Acad Sci USA 2010; 7: 15963-15968.

17. Lafrenière RG, Cader MZ, Poulin JF, et al. A dominantnegative mutation in the TRESK potassium channel is linked to familial migraine with aura. Nat Med 2010; 16: 1157-1160.

18. Lea RA, Ovcaric M, Sundholm J, et al. The methylenetetrahydrofolate reductase gene variant $\mathrm{C} 677 \mathrm{~T}$ influences susceptibility to migraine with aura. $B M C$ Med 2004; $2: 3$. 
19. Scher AI, Terwindt GM, Verschuren WM, et al. Migraine and MTHFR C677T genotype in a population-based sample. Ann Neurol 2006; 59: 372-375.

20. Rubino E, Ferrero M, Rainero I, et al. Association of the C677T polymorphism in the MTHFR gene with migraine: A meta-analysis. Cephalalgia 2009; 29: 818-825.

21. Samaan Z, Gaysina D, Cohen-Woods S, et al. Methylenetetrahydrofolate reductase gene variant (MTHFR C677T) and migraine: A case control study and metaanalysis. BMC Neurol 2011; 11: 66.

22. Fernandez F, Colson N, Quinlan S, et al. Association between migraine and a functional polymorphism at the dopamine beta-hydroxylase locus. Neurogenetics 2009; 10: 199-208.

23. Todt U, Netzer C, Toliat M, et al. New genetic evidence for involvement of the dopamine system in migraine with aura. Hum Genet 2009; 125: 265-279.

24. Corominas R, Ribases M, Camiña M, et al. Two-stage case-control association study of dopamine-related genes and migraine. BMC Med Genet 2009; 21: 10:95.

25. Tikka-Kleemola $\mathrm{P}$, Kaunisto MA, Hämäläinen E, et al. Genetic association study of endothelin-1 and its receptors EDNRA and EDNRB in migraine with aura. Cephalalgia 2009; 29: 1224-1231.

26. Tropeano M, Wöber-Bingöl C, Karwautz A, et al. Association analysis of $S T X 1 A$ gene variants in common forms of migraine. Cephalalgia 2012; 32: 203-212.

27. Carreño O, Corominas R, Fernández-Morales J, et al. SNP variants within the vanilloid TRPVI and TRPV3 receptor genes are associated with migraine in the Spanish population. Am J Med Genet B Neuropsychiatr Genet 2012; 159B: 94-103.

28. Oterino A, Toriello M, Cayón A, et al. Multilocus analyses reveal involvement of the ESR1, ESR2, and FSHR genes in migraine. Headache 2008; 48: 1438-1450.

29. Colson NJ, Lea RA, Quinlan S, et al. The estrogen receptor 1 G594A polymorphism is associated with migraine susceptibility in two independent case/control groups. Neurogenetics 2004; 5: 129-133.

30. Kaunisto MA, Kallela M, Hämäläinen E, et al. Testing of variants of the MTHFR and ESRI genes in 1798 Finnish individuals fails to confirm the association with migraine with aura. Cephalalgia 2006; 26: 1462-1472.

31. Colson NJ, Lea RA, Quinlan S, et al. Investigation of hormone receptor genes in migraine. Neurogenetics 2005; 6: 17-23.

32. Rainero I, Grimaldi LM, Salani G, et al. Association between the tumor necrosis factor-alpha $-308 \mathrm{G} / \mathrm{A}$ gene polymorphism and migraine. Neurology 2004; 62: 141-143.

33. Schürks M, Rist PM and Kurth T. Sex hormone receptor gene polymorphisms and migraine: A systematic review and meta-analysis. Cephalalgia 2010; 30 : 1306-1328.

34. Jung A, Huge A, Kuhlenbäumer G, et al. Genetic TPH2 variants and the susceptibility for migraine: association of a TPH2 haplotype with migraine without aura. $J$ Neural Transm 2010; 117: 1253-1260.

35. Lee KA, Jang SY, Sohn KM, et al. Association between a polymorphism in the lymphotoxin-a promoter region and migraine. Headache 2007; 47: 1056-1062.

36. McCarthy LC, Hosford DA, Riley JH, et al. Singlenucleotide polymorphism alleles in the insulin receptor gene are associated with typical migraine. Genomics 2001; 78: 135-149.

37. Netzer C, Freudenberg J, Heinze A, et al. Replication study of the insulin receptor gene in migraine with aura. Genomics 2008; 91: 503-507.

38. Headache Classification Committee of the International Headache Society. The International Classification of Headache Disorders, 2nd edition. Cephalalgia 2004; 24: $1-160$.

39. van Oosterhout WP, Weller CM, Stam AH, et al. Validation of the web-based LUMINA questionnaire for recruiting large cohorts of migraineurs. Cephalalgia 2011; 31: 1359-1367.

40. Hofman A, van Duijn CM, Franco OH, et al. The Rotterdam Study: 2012 objectives and design update. Eur $J$ Epidemiol 2011; 26: 657-686.

41. Krawczak M, Nikolaus S, von Eberstein $H$, et al. PopGen: Population-based recruitment of patients and controls for the analysis of complex genotype-phenotype relationships. Community Genet 2006; 9: 55-61.

42. Kallela M, Wessman $\mathbf{M}$ and Färkkilä $\mathbf{M}$. Validation of a migraine-specific questionnaire for use in family studies. Eur J Neurol 2001; 8: 61-66.

43. Naukkarinen J, Surakka I, Pietiläinen KH, et al. Use of genome-wide expression data to mine the "Gray Zone" of GWA studies leads to novel candidate obesity genes. PLoS Genet 2010; 6: e1000976.

44. Barker DJ, Osmond C, Forsén TJ, et al. Trajectories of growth among children who have coronary events as adults. N Engl J Med 2005; 353: 1802-1809.

45. Muglia P, Tozzi F, Galwey NW, et al. Genome-wide association study of recurrent major depressive disorder in two European case-control cohorts. Mol Psychiatry 2010; 15: 589-601.

46. Wichmann HE, Gieger C, Illig T, et al. KORA-gen-resource for population genetics, controls and a broad spectrum of disease phenotypes. Gesundheitswesen 2005; 67(Suppl 1): S26-S30.

47. Schmermund A, Möhlenkamp S, Stang A, et al. Assessment of clinically silent atherosclerotic disease and established and novel risk factors for predicting myocardial infarction and cardiac death in healthy middle-aged subjects: Rationale and design of the Heinz Nixdorf RECALL Study. Risk Factors, Evaluation of Coronary Calcium and Lifestyle. Am Heart J 2002; 144 : 212-218.

48. Purcell S, Cherny SS and Sham PC. Genetic Power Calculator: Design of linkage and association genetic mapping studies of complex traits. Bioinformatics 2003; 19 : 149-150. 
49. Gourraud PA, Khankhanian P, Cereb N, et al. HLA diversity in the 1000 genomes dataset. PLoS One 2014; 9: e97282.

50. Schürks M, Rist PM and Kurth T. MTHFR $677 \mathrm{C}>\mathrm{T}$ and $A C E \mathrm{D} / \mathrm{I}$ polymorphisms in migraine: A systematic review and meta-analysis. Headache 2010; 50: 588-599.

51. The International HapMap Consortium. Integrating common and rare genetic variation in diverse human populations. Nature 2010; 467: 52-58.
52. Button KS, Ioannidis JP, Mokrysz C, et al. Power failure: Why small sample size undermines the reliability of neuroscience. Nat Rev Neurosci 2013; 14: 365-376.

53. Hirschhorn JN, Lohmueller K, Byrne E, et al. A comprehensive review of genetic association studies. Genet Med 2002; 4: 45-61. 